\title{
The Audio Frequency Conductance Study of Some Metal Succinate Salts in Aqueous Medium at Different Temperatures (Part I: Magnesium, Manganese (II), Barium and Copper Succinates)
}

\author{
Kosrat N. Kaka, ${ }^{1}$ Anis A. Al-Najar, ${ }^{2}$ and Wali M. Hamad ${ }^{3}$ \\ ${ }^{1}$ Department of Chemistry, College of Science, University of Koya, Koya Town, Iraq \\ ${ }^{2}$ Department of Chemistry, College of Science, University of Basrah, Basrah City, Iraq \\ ${ }^{3}$ Koya Technical Institute, Department of oil Refinery, Koya Town, Iraq \\ Correspondence should be addressed to Anis A. Al-Najar; anisalnajar@yahoo.com
}

Received 5 January 2012; Revised 25 June 2012; Accepted 26 June 2012

Academic Editor: Jose Corchado

Copyright ( 2013 Kosrat N. Kaka et al. This is an open access article distributed under the Creative Commons Attribution License, which permits unrestricted use, distribution, and reproduction in any medium, provided the original work is properly cited.

\begin{abstract}
The audio electrical conductances of aqueous solutions of magnesium, manganese II, barium, and copper succinates have been measured at various temperatures in the range of $298.15 \mathrm{~K}$ to $313.15 \mathrm{~K}$, using an audio frequency conductance bridge. The evaluation of conductance data was carried out by minimisation technique using the theoretical equations of the complete and modified forms of Pitts (P) and Fuoss-Hsia (F-H), each a three-parameter equation, association constant $\left(K_{A}\right)$, molar conductance $\left(\Lambda_{m}\right)$, and distance parameter $(a)$. Quantitative results showed that these salts do not behave as "strong" electrolytes, and that their dissociations are far from complete. The abnormally low conductances of these electrolytes are not due to the presence of electrically neutral molecules but to the ion-pair formation. The Walden product values, as well as the standard thermodynamics functions $\left(\Delta H^{\circ}, \Delta G^{\circ}\right.$, $\Delta S^{\circ}$ ) for the association reaction at the four temperatures studied, have been evaluated.
\end{abstract}

\section{Introduction}

The conductance of any electrolyte at infinite dilution is generally recognised to be dependent upon temperature, viscosity, and dielectric constant. Also, it is well established that the extent of association of a series of electrolytes in different solvents is specific for any ion-solvent combination, rather than being dielectric constant dependent. Information on ion-ion and ion-solvent and interactions can be obtained from conductivity measurement [1-4]. In a series of conductance studies, there have been numerous investigations of association behavior of $1: 1$ electrolytes in aqueous and binary mixed solvents.

On the other hand, the conductance behavior of $2: 2$ electrolytes (specially salts of dicarboxylic acids) has received relatively little attention. This is largely due to the difficulty encountered in analysing such data since the usual methods require an arbitrary choice for some of the parameters needed in the analysis. However, there were no available cited recent studies in the literature concerning the association of the bivalent cations with bivalent organic ligands. In part I of this paper, we report conductance measurement of magnesium, manganese II, barium, and copper succinates in aqueous medium at various temperatures in the range 298.15-313.15 K. Metal succinates play an important role in biological and industrial processes [5-8]. Four currently used conductance equations, the complete and expanded forms of both Fuoss-Hsia and Pitts equations, have been used to analyse conductance data for these succinate salts. Also, the thermodynamic parameters $\Delta H^{\circ}, \Delta G^{\circ}$, and $\Delta S^{\circ}$ were evaluated by investigating the process over a certain temperature range. In addition, Walden product was derived and discussed.

\section{Experimental}

Measurements were made at a range of temperatures between 298.15 and $313.15 \mathrm{~K}$ with Oakton-con510 audio frequency 
TABle 1: Experimental conductance data for Ba succinate.

\begin{tabular}{|c|c|c|c|c|c|c|c|}
\hline \multicolumn{2}{|c|}{$298.15 \mathrm{~K}$} & \multicolumn{2}{|c|}{$303.15 \mathrm{~K}$} & \multicolumn{2}{|c|}{$308.15 \mathrm{~K}$} & \multicolumn{2}{|c|}{$313.15 \mathrm{~K}$} \\
\hline Conc. $* 10^{3}$ & $\Lambda$ & Conc. $* 10^{3}$ & $\Lambda$ & Conc. $* 10^{3}$ & $\Lambda$ & Conc. $* 10^{3}$ & $\Lambda$ \\
\hline 0.56411 & 199.190 & 0.50910 & 209.414 & 0.70798 & 202.902 & 0.62824 & 208.904 \\
\hline 0.74531 & 193.356 & 0.62278 & 204.192 & 0.75117 & 201.282 & 0.66546 & 207.388 \\
\hline 0.79218 & 192.096 & 0.67767 & 202.628 & 0.79106 & 200.014 & 0.70088 & 206.188 \\
\hline 0.83645 & 191.262 & 0.77676 & 199.560 & 0.82796 & 199.898 & 0.73761 & 204.738 \\
\hline 0.87756 & 190.604 & 0.82113 & 197.964 & 0.86275 & 197.870 & 0.77281 & 203.830 \\
\hline 0.91808 & 190.128 & 0.86265 & 195.676 & 0.89685 & 196.440 & 0.80525 & 202.728 \\
\hline 0.95837 & 189.466 & 0.90303 & 195.570 & 0.93330 & 195.458 & 0.83474 & 202.112 \\
\hline 1.03271 & 187.164 & 0.97511 & 193.654 & 0.96168 & 194.830 & 0.86236 & 201.070 \\
\hline 1.09135 & 186.406 & 1.00758 & 192.836 & 0.98779 & 193.896 & 0.88292 & 200.514 \\
\hline 1.10711 & 186.808 & 1.03740 & 190.804 & 1.01067 & 193.368 & 0.90937 & 199.260 \\
\hline & & 1.06599 & 190.326 & & & & \\
\hline
\end{tabular}

$\Lambda\left(\mathrm{ohm}^{-1} \mathrm{~cm}^{2} \mathrm{~mol}^{-1}\right)$; Conc.: concentration $\left(\mathrm{mol} \cdot \mathrm{dm}^{-3}\right)$.

TABLE 2: Experimental conductance data for $\mathrm{Cu}$ succinate.

\begin{tabular}{|c|c|c|c|c|c|c|c|}
\hline \multicolumn{2}{|c|}{$298.15 \mathrm{~K}$} & \multicolumn{2}{|c|}{$303.15 \mathrm{~K}$} & \multicolumn{2}{|c|}{$308.15 \mathrm{~K}$} & \multicolumn{2}{|c|}{$313.15 \mathrm{~K}$} \\
\hline Conc. $* 10^{3}$ & $\Lambda$ & Conc. $* 10^{3}$ & $\Lambda$ & Conc. $* 10^{3}$ & $\Lambda$ & Conc. $* 10^{3}$ & $\Lambda$ \\
\hline 0.11875 & 104.322 & 0.22592 & 88.190 & 0.26685 & 83.448 & 0.40075 & 76.194 \\
\hline 0.17218 & 92.200 & 0.34929 & 73.130 & 0.32137 & 77.388 & 0.45082 & 72.174 \\
\hline 0.40553 & 66.350 & 0.40233 & 69.116 & 0.37259 & 72.824 & 0.50755 & 68.362 \\
\hline 0.51577 & 60.392 & 0.45097 & 66.048 & 0.41829 & 69.286 & 0.55875 & 65.358 \\
\hline 0.57000 & 57.934 & 0.55605 & 60.490 & 0.47100 & 66.172 & 0.60713 & 63.150 \\
\hline 0.62195 & 56.106 & 0.60216 & 58.582 & 0.51965 & 63.582 & 0.65040 & 61.270 \\
\hline 0.67296 & 54.482 & 0.69118 & 55.478 & 0.56405 & 61.622 & 0.69433 & 59.530 \\
\hline 0.72053 & 53.198 & 0.72973 & 54.188 & 0.60434 & 59.882 & 0.73652 & 58.098 \\
\hline 0.76804 & 52.312 & 0.76627 & 53.302 & 0.64214 & 58.666 & 0.80993 & 55.852 \\
\hline 0.80697 & 51.142 & 0.79876 & 52.208 & 0.67746 & 57.336 & 0.87104 & 54.114 \\
\hline 0.84202 & 50.218 & 0.83003 & 51.590 & 0.71418 & 56.100 & 0.89970 & 53.402 \\
\hline 0.87450 & 49.544 & 0.88436 & 50.392 & 0.78025 & 54.250 & 0.92202 & 52.900 \\
\hline 0.90625 & 48.870 & 0.90694 & 49.998 & 0.80909 & 53.506 & 0.94071 & 52.430 \\
\hline 0.93728 & 48.336 & 0.923890 & 49.530 & & & & \\
\hline
\end{tabular}

$\Lambda\left(\mathrm{ohm}^{-1} \mathrm{~cm}^{2} \mathrm{~mol}^{-1}\right)$; Conc.: concentration $\left(\mathrm{mol} \cdot \mathrm{dm}^{-3}\right)$.

TABLE 3: Experimental conductance data for Mg succinate.

\begin{tabular}{|c|c|c|c|c|c|c|c|}
\hline \multicolumn{2}{|c|}{$298.15 \mathrm{~K}$} & \multicolumn{2}{|c|}{$303.15 \mathrm{~K}$} & \multicolumn{2}{|c|}{$308.15 \mathrm{~K}$} & \multicolumn{2}{|c|}{$313.15 \mathrm{~K}$} \\
\hline Conc. $* 10^{3}$ & $\Lambda$ & Conc. $* 10^{3}$ & $\Lambda$ & Conc. $* 10^{3}$ & $\Lambda$ & Conc. $* 10^{3}$ & $\Lambda$ \\
\hline 0.32106 & 152.146 & 0.53293 & 167.682 & 0.56479 & 171.312 & 0.06619 & 222.736 \\
\hline 0.38543 & 150.700 & 0.62320 & 165.106 & 0.65514 & 166.354 & 0.23327 & 200.850 \\
\hline 0.44357 & 147.958 & 0.73614 & 159.570 & 0.77615 & 163.214 & 0.52183 & 181.330 \\
\hline 0.49967 & 144.364 & 0.95818 & 153.276 & 0.88264 & 159.736 & 0.72094 & 172.758 \\
\hline 0.56965 & 141.704 & 1.07099 & 150.494 & 1.01288 & 157.180 & 0.81690 & 169.664 \\
\hline 0.63635 & 139.118 & 1.19035 & 147.426 & 1.13065 & 153.924 & 0.93341 & 165.490 \\
\hline 0.69845 & 136.062 & 1.32226 & 145.708 & 1.25809 & 151.156 & 1.16002 & 160.302 \\
\hline 0.77167 & 133.942 & 1.44684 & 143.592 & 1.40034 & 148.436 & 1.41143 & 155.162 \\
\hline 0.83990 & 131.736 & 1.57115 & 142.498 & 1.53116 & 146.800 & 1.53523 & 152.818 \\
\hline 0.91505 & 129.448 & 1.83767 & 137.972 & 1.66882 & 144.824 & 1.66980 & 149.540 \\
\hline
\end{tabular}

$\Lambda\left(\mathrm{ohm}^{-1} \mathrm{~cm}^{2} \mathrm{~mol}^{-1}\right)$; Conc.: concentration $\left(\mathrm{mol} \cdot \mathrm{dm}^{-3}\right)$. 


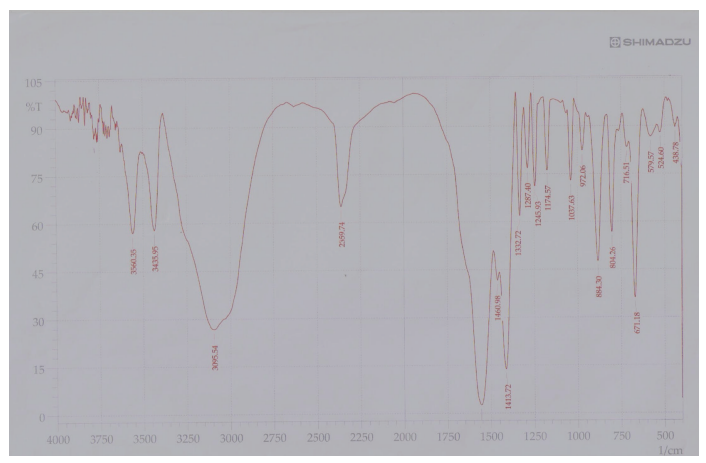

Figure 1: FT-IR spectra for Mg succinate.

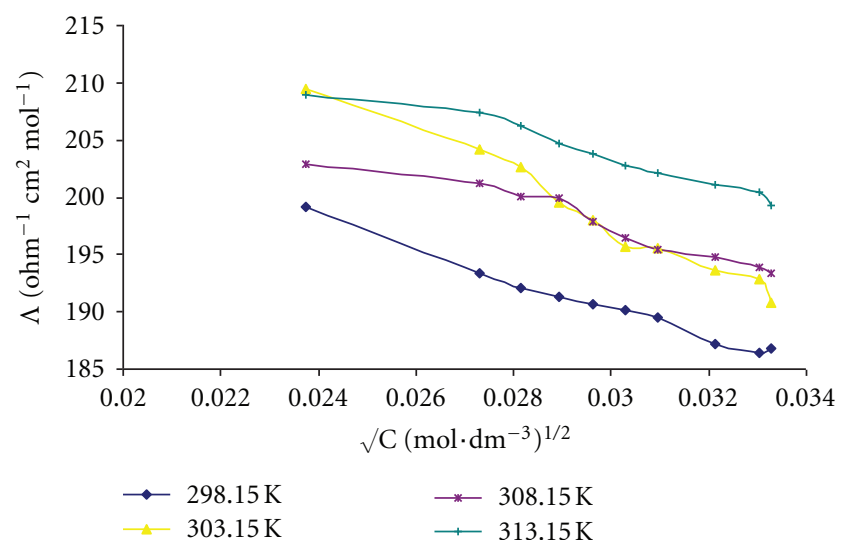

FIGURE 2: Molar conductance versus square root of concentration for Ba-succinate at different temperatures.

bridge of low impedance. It combines speed and simplicity of operation with $0.05 \%$ accuracy. The cell used for measuring conductances has been described elsewhere [9]. The cell constant (as determined by standard solutions of potassium chloride) was $1.04079 \mathrm{~cm}^{-1}$. The method used for measuring conductances has been described [9].

\section{Materials}

The $\mathrm{KCl}$ used in this work was purified and used according to the literature [9]. Magnesium succinate was prepared by addition of clean and dried magnesium ribbon to a solution of succinic acid. The PH of solution was continuously tested until the solution became neutral. Then the mixture was filtered to remove the excess of metal added, after which the solvent was evaporated on a water bath. The product was recrystallized twice from conductivity water and dried by air at room temperature. The final product was a white crystalline powder as the tetrahydrate. The composition of the salt was determined by elemental analysis. The salt was further analysed for magnesium by titration with the disodium salt of ethylenediaminetetraacetic acid (EDTA) using eriochrome black $\mathrm{T}$ as indicator [10]. Elemental analysis confirmed the composition with experimental/calculated values (mass percent): C 23.4/22.5, H 6.6/5.7, and Mg 11.38/11.24. FT-IR

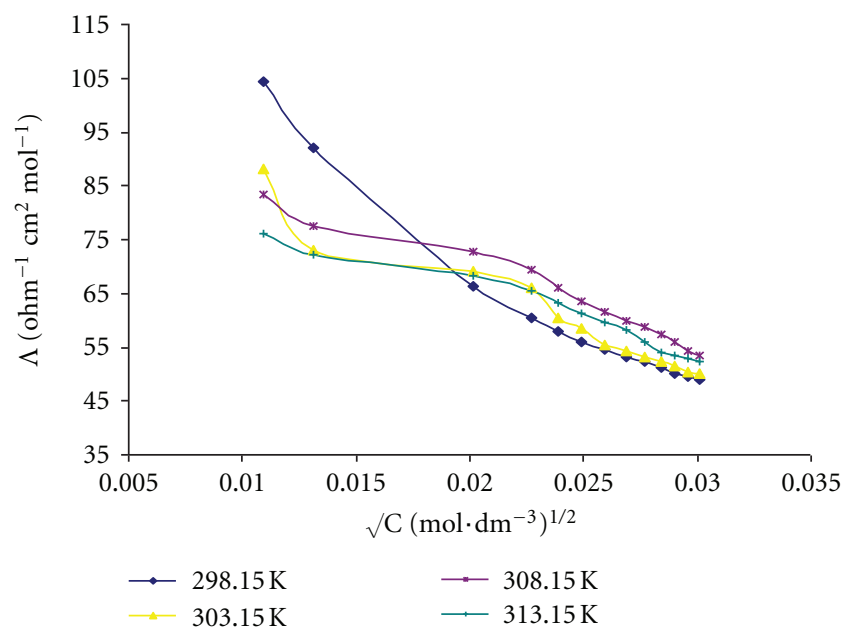

FIGURE 3: Molar conductance versus square root of concentration for $\mathrm{Cu}$-succinate at different temperatures.

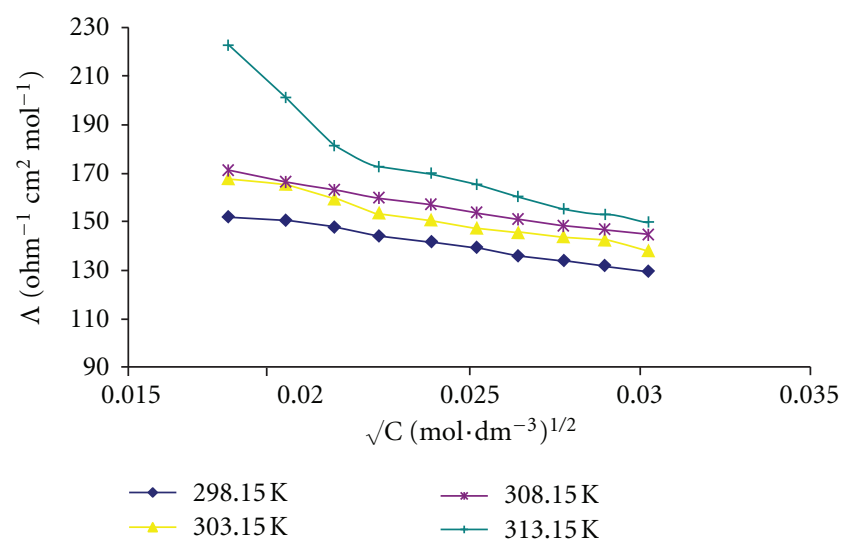

FIGURE 4: Molar conductance versus square root of concentration for Mg-succinate at different temperatures.

exhibits the following absorption bands (KBr pellet, $\left.v / \mathrm{cm}^{-1}\right)$ : narrow $v(\mathrm{O}-\mathrm{H})$ bands at 3560 and $3435 \mathrm{~cm}^{-1}$; associated with the existence of hydrogen bonds; stretching frequencies corresponding to the carboxylate ion $v\left(\mathrm{CO}_{2}^{-}\right)$and $v(\mathrm{C}-\mathrm{O})$ at $1560,1460,1413,1332,1287$, and $1245 \mathrm{~cm}^{-1}$; the $1174 \mathrm{~cm}^{-1}$ 
TABLE 4: Experimental conductance data for Mn-succinate.

\begin{tabular}{|c|c|c|c|c|c|c|c|}
\hline \multicolumn{2}{|c|}{$298.15 \mathrm{~K}$} & \multicolumn{2}{|c|}{$303.15 \mathrm{~K}$} & \multicolumn{2}{|c|}{$308.15 \mathrm{~K}$} & \multicolumn{2}{|c|}{$313.15 \mathrm{~K}$} \\
\hline Conc. $* 10^{3}$ & $\Lambda$ & Conc. $* 10^{3}$ & $\Lambda$ & Conc. $* 10^{3}$ & $\Lambda$ & Conc. $* 10^{3}$ & $\Lambda$ \\
\hline 0.43244 & 162.542 & 0.19989 & 182.826 & 0.10976 & 197.114 & 0.34023 & 176.396 \\
\hline 0.51084 & 158.992 & 0.31941 & 171.114 & 0.14567 & 191.570 & 0.39961 & 169.720 \\
\hline 0.60785 & 153.734 & 0.37725 & 167.640 & 0.33335 & 170.980 & 0.47590 & 167.116 \\
\hline 0.69413 & 149.622 & 0.46203 & 162.784 & 0.39655 & 167.354 & 0.53986 & 163.222 \\
\hline 1.01124 & 139.240 & 0.54652 & 159.042 & 0.47351 & 160.484 & 0.61789 & 159.032 \\
\hline 1.12663 & 135.140 & 1.08379 & 138.060 & 0.54065 & 159.326 & 0.69363 & 155.548 \\
\hline 1.24575 & 132.034 & 1.20277 & 134.786 & 0.69278 & 148.376 & 0.77113 & 151.386 \\
\hline 1.37319 & 129.446 & 1.32895 & 131.778 & 0.77883 & 146.682 & 0.85864 & 147.472 \\
\hline 1.49389 & 127.348 & 1.56919 & 125.532 & 0.87155 & 141.826 & 0.93962 & 146.116 \\
\hline 1.59976 & 125.100 & 1.69673 & 124.530 & 1.25557 & 131.398 & 1.02234 & 143.202 \\
\hline
\end{tabular}

$\Lambda\left(\mathrm{ohm}^{-1} \mathrm{~cm}^{2} \mathrm{~mol}^{-1}\right)$; Conc.: concentration $\left(\mathrm{mol} \cdot \mathrm{dm}^{-3}\right)$.

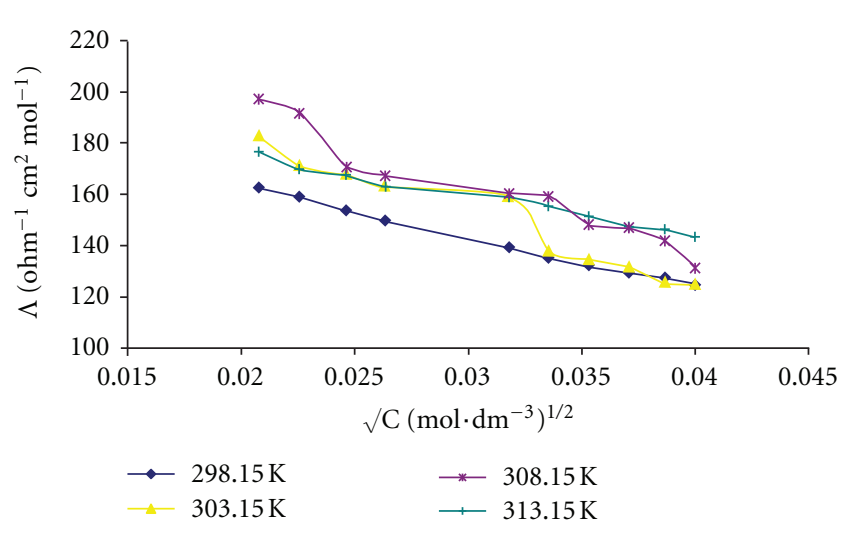

FIGURE 5: Molar conductance versus square root of concentration for Mn-succinate at different temperatures.

absorption band is associated with $v(\mathrm{C}-\mathrm{C})$ and the following absorptions with metal oxygen bonding and with $v(\mathrm{C}-\mathrm{H})$ 1037, 972, 884, 804, 716, 671, 579, 524, and $438 \mathrm{~cm}^{-1}$ [11]. The $\mathrm{H}$-NMR was recorded in $\mathrm{D}_{2} \mathrm{O}$ solvent $\delta_{H}=2.3 \mathrm{ppm}$.

Manganese succinate was prepared by the method described by Vogel [12] with some modification. "Analar" grade manganese chloride solution was added to a solution of sodium succinate. The reaction here was continued until the $\mathrm{pH}$ of the mixture became neutral. The mixture was heated on a water bath until a quarter of it was gained. The remaining solution was left for 24 hours. Then light pink crystals formed. The mixture was filtered off. The product was washed with chilled conductivity water until it became free from chloride ions; after that the final product was dried by air at room temperature. Elemental analysis confirmed the composition with experimental/calculated values (mass percent): C 20.3/19.8, H 5.7/5.0. FT-IR spectra exhibit the following absorption bands $\left(\mathrm{KBr}\right.$ pellet, $\left.v / \mathrm{cm}^{-1}\right): v(\mathrm{O}-\mathrm{H})$ bands at 3505 and $3417 \mathrm{~cm}^{-1}$; stretching frequencies corresponding to the carboxylate ion $v\left(\mathrm{CO}_{2}\right)$ and $v(\mathrm{CO})$ at 1657, 1552, 1462, 1406,
1329,1285 , and $1244 \mathrm{~cm}^{-1}$; the $1172 \mathrm{~cm}^{-1}$ absorption band is associated with $v(\mathrm{C}-\mathrm{C})$ and the following absorptions with metal-oxygen bonding and with $v(\mathrm{C}-\mathrm{H}) 1037,970,856,798$, 671 , and $525 \mathrm{~cm}^{-1}$. The H-NMR $\delta_{H}=2.3 \mathrm{ppm}$.

The same method [12] was carried out for the preparation of barium succinate. "Analar" grade barium chloride dihydrate solution was added to a solution of sodium succinate, and the rest was that as described before for manganese succinate. The product was a white crystalline powder. Elemental analysis confirmed the composition with experimental/calculated values (mass percent): C 15.8/16.6, H 2.3/2.6. FT-IR spectra exhibit the following absorption bands ( $\mathrm{KBr}$ pellet, $\left.v / \mathrm{cm}^{-1}\right): v(\mathrm{O}-\mathrm{H}) 3550,3435 \mathrm{~cm}^{-1}$; stretching frequencies corresponding to the carboxylate ion $v\left(\mathrm{CO}_{2}^{-}\right)$ and $v(\mathrm{CO})$ at $1550,1397,1328,1286$, and $1239 \mathrm{~cm}^{-1}$; the $1165 \mathrm{~cm}^{-1}$ absorption band is associated with $v(\mathrm{C}-\mathrm{C})$ and the following absorptions with metal-oxygen bonding and with $v(\mathrm{C}-\mathrm{H}), 1032,963,930,803,657,490$, and 464 . The H-NMR $\delta_{H}=2.30 \mathrm{ppm}$.

The copper succinate was prepared by reaction stochiometric amounts of both a solution of succinic acid and copper metal. The solution was heated with continuous stirring at $348.15-353.15 \mathrm{~K}$ for a period of 3-4 hours. A blue solution appeared which was evaporated on a water bath after filtering and removing the excess metal copper. The product was a blue powder and dried afterwards for 24 hours, as the dihydrate. Elemental analysis confirmed the composition with experimental/calculated values (mass percent): C $22.3 / 22.3$, $\mathrm{H}$ 3.2/3.7. The FT-IR spectra exhibit the following absorption bands $\left(\mathrm{KBr}\right.$ pellet, $\left.v / \mathrm{cm}^{-1}\right): v(\mathrm{O}-\mathrm{H})$ bands at 3579,3483 , and $3380 \mathrm{~cm}^{-1}$ associated with the existence of hydrogen bonds, stretching frequencies corresponding to the carboxylate ion $v\left(\mathrm{CO}_{2}^{-}\right)$and $v(\mathrm{C}-\mathrm{O})$ at $1625,1446,1329$, and $1390 \mathrm{~cm}^{-1}$; the $1185 \mathrm{~cm}^{-1}$ absorbance band is associated with $v(\mathrm{C}-\mathrm{C})$ and the following absorptions with metal oxygen bonding and with $v(\mathrm{C}-\mathrm{H}), 1001,973,886,730,694,618,581$, and 520 . The $\mathrm{H}$-NMR was recorded in $\mathrm{D}_{2} \mathrm{O}$ solvent $\delta_{H}=2.30 \mathrm{ppm}$. 
TABLE 5: Best fit results for Ba-succinate.

\begin{tabular}{|c|c|c|c|c|c|}
\hline Temps. & Parameter & F-H complete ${ }^{*}$ & F-H modified ${ }^{*}$ & Pitts complete & Pitts modified \\
\hline \multirow{6}{*}{$298.15 \mathrm{~K}$} & $\Lambda_{0}$ & 240.00 & 238.80 & $231.40-232.60$ & 236.40 \\
\hline & $K_{A}$ & 135.00 & 114.00 & $275.00-285.00$ & 78.00 \\
\hline & $a$ & 0.99 & 1.01 & 0.30 & 0.69 \\
\hline & $D_{\text {salt }} * 10^{-5}$ & 1.597 & 1.589 & 1.544 & 1.573 \\
\hline & $\sigma$ & 0.1859 & 0.2110 & 0.3086 & 0.2727 \\
\hline & $\eta \Lambda_{0}$ & 2.13816 & 2.12747 & 2.06689 & 2.10609 \\
\hline \multirow{6}{*}{$303.15 \mathrm{~K}$} & $\Lambda_{0}$ & 261.20 & 259.20 & $250.80-251.00$ & 254.20 \\
\hline & $K_{A}$ & 182.0 & 216.0 & $380.0-382.0$ & 81.0 \\
\hline & $a$ & 0.70 & 1.39 & 0.30 & 0.70 \\
\hline & $D_{\text {salt }} * 10^{-5}$ & 1.767 & 1.754 & 1.698 & 1.720 \\
\hline & $\sigma$ & 0.2410 & 0.2339 & 0.2867 & 0.2267 \\
\hline & $\eta \Lambda_{0}$ & 2.08490 & 2.06893 & 2.00268 & 2.02902 \\
\hline \multirow{6}{*}{$308.15 \mathrm{~K}$} & $\Lambda_{0}$ & 279.80 & 270.00 & $261.60-261.80$ & 263.60 \\
\hline & $K_{A}$ & 420.0 & 263.0 & 430.0 & 110.0 \\
\hline & $a$ & 1.41 & 1.39 & 0.70 & 0.30 \\
\hline & $D_{\text {salt }} * 10^{-5}$ & 1.916 & 1.857 & 1.800 & 1.813 \\
\hline & $\sigma$ & 0.1866 & 0.2308 & 0.2889 & 0.2190 \\
\hline & $\eta \Lambda_{0}$ & 2.02239 & 1.95156 & 1.89157 & 1.90530 \\
\hline \multirow{6}{*}{$313.15 \mathrm{~K}$} & $\Lambda_{0}$ & 288.80 & 276.00 & 275.20 & 272.00 \\
\hline & $K_{A}$ & 455.0 & 264.7 & 540.0 & 150.0 \\
\hline & $a$ & 1.40 & 1.39 & 0.35 & 0.41 \\
\hline & $D_{\text {salt }} * 10^{-5}$ & 2.019 & 1.929 & 1.924 & 1.901 \\
\hline & $\sigma$ & 0.2509 & 0.3156 & 0.4114 & 0.3189 \\
\hline & $\eta \Lambda_{0}$ & 1.88875 & 1.80504 & 1.79981 & 1.77888 \\
\hline
\end{tabular}

* Preferred values

Units of $\Lambda_{0}: \mathrm{ohm}^{-1} \mathrm{~cm}^{2} \mathrm{~mol}^{-1}, K_{A}: \mathrm{dm}^{3} \mathrm{~mol}^{-1}, a: \mathrm{nm}, D_{\text {salt }}: \mathrm{cm}^{2} \mathrm{~s}^{-1}, \sigma$ : unitless, and $\eta \Lambda_{0}: \mathrm{ohm}^{-1} \mathrm{~cm}^{2} \mathrm{~mol}^{-1} \mathrm{Cp}$.

All stock solutions were prepared by weight, and all measurements were done using the weight dilution technique.

Figure 1 illustrates an example of FT-IR run.

\section{Result and Discussion}

The measured molar conductances $\Lambda$ and the corresponding concentrations $C$ in mol. $\mathrm{dm}^{-3}$ at four different temperatures are given in Tables 1, 2, 3, and 4. These data were analyzed using the complete and modified forms of both F-H and $\mathrm{P}$ equations. For the interpretation of the characteristic parameters of an electrolyte solution from conductance data, a minimisation technique has been used in terms of $K_{A}, \Lambda_{0}$, and $a$. For analysis of each set of data, $C_{j}, \Lambda_{j}(j=1,2, \ldots, N)$, a Fortran computer program has been written. The results of minimisation technique for the best fit values of the three parameters $K_{A}, \Lambda_{0}$, and $a$ are listed in Tables $5,6,7$, and 8 together with diffusion coefficient $\left(D_{\text {salt }}\right)$.

Walden product and the corresponding values of the standard deviation $\sigma$ are given by

$$
\sigma=\left[\frac{S^{2}}{N}\right]^{1 / 2}
$$

where $S^{2}$ is defined by

$$
S^{2}=\sum_{j=1}^{N}\left(\Lambda_{\text {calculated }}-\Lambda_{j}\right)^{2} .
$$

Standard thermodynamic quantities for the association reaction are obtained from the temperature dependence of the association constant $K_{A}$. The standard enthalpy change $\left(\Delta H^{\circ}\right)$ was determined from the slope of $\log K_{A}$ versus $1 / T$ [13] as follows:

$$
\log K_{A}=\left(-\frac{\Delta H}{2.303 R T}\right)+\text { constant, }
$$

and the standard Gibbs energy $\left(\Delta G^{\circ}\right)$ and entropy $\left(\Delta S^{\circ}\right)$ changes were calculated using the well-known relations

$$
-R T \ln K_{A}=\Delta G^{\circ}=\Delta H^{\circ}-T \Delta S^{\circ} .
$$

Also the diffusion coefficients of the salts $\left(D_{\text {salt }}\right)$ can be founded from the equation [14]

$$
D_{\text {salt }}=\left(\frac{(R * T)}{F^{2}}\right)\left(\frac{\Lambda_{0}}{Z}\right) \text {, }
$$

where $R=8.314 \mathrm{j} \mathrm{K}^{-1}$ mole $^{-1}, F=96500 \mathrm{C}$, and $Z=2$, while the Walden's product can be calculated as a function of temperature by using

$$
\Lambda_{0}(T) \eta(T)=\text { constant. }
$$


TABLE 6: Best fit results for $\mathrm{Cu}$-succinate.

\begin{tabular}{|c|c|c|c|c|c|}
\hline Temps. & Parameter & F-H complete ${ }^{*}$ & F-H modified ${ }^{*}$ & Pitts complete & Pitts modified \\
\hline \multirow{6}{*}{$298.15 \mathrm{~K}$} & $\Lambda_{0}$ & 226.20 & 221.40 & $214.60-215.00$ & 217.00 \\
\hline & $K_{A}$ & 11600.0 & 10510.0 & $11100.0-11108.0$ & 10050.0 \\
\hline & $a$ & 1.01 & 0.71 & 0.10 & 0.31 \\
\hline & $D_{\text {salt }} * 10^{-5}$ & 1.505 & 1.473 & 1.429 & 1.444 \\
\hline & $\sigma$ & 0.1723 & 0.2198 & 0.2417 & 0.1998 \\
\hline & $\eta \Lambda_{0}$ & 2.01522 & 1.97245 & 1.91365 & 1.93325 \\
\hline \multirow{6}{*}{$303.15 \mathrm{~K}$} & $\Lambda_{0}$ & 271.40 & 267.60 & 267.80 and 268.00 & 262.20 \\
\hline & $K_{A}$ & 16300.0 & 15020.0 & 17000.0 & 14550.0 \\
\hline & $a$ & 0.69 & 0.31 & 1.00 & 0.30 \\
\hline & $D_{\text {salt }} * 10^{-5}$ & 1.836 & 1.811 & 1.812 & 1.774 \\
\hline & $\sigma$ & 0.1800 & 0.1971 & 0.2513 & 0.1869 \\
\hline & $\eta \Lambda_{0}$ & 2.16632 & 2.13598 & 2.13838 & 2.09288 \\
\hline \multirow{6}{*}{$308.15 \mathrm{~K}$} & $\Lambda_{0}$ & 287.80 & 279.60 & $277.80-278.10$ & 280.40 \\
\hline & $K_{A}$ & 18100.0 & 15800.0 & $17950.0-18050.0$ & 16200.0 \\
\hline & $a$ & 1.01 & 0.31 & 0.30 & 0.31 \\
\hline & $D_{\text {salt }} * 10^{-5}$ & 1.980 & 1.923 & 1.912 & 1.929 \\
\hline & $\sigma$ & 0.1130 & 0.2095 & 0.2569 & 0.1770 \\
\hline & $\eta \Lambda_{0}$ & 2.08022 & 2.02095 & 2.00902 & 2.02673 \\
\hline \multirow{6}{*}{$313.15 \mathrm{~K}$} & $\Lambda_{0}$ & 359.20 & 345.00 & $331.70-332.30$ & 344.80 \\
\hline & $K_{A}$ & 25300.0 & 22100.0 & $22700.0-22900.0$ & 22450.0 \\
\hline & $a$ & 0.29 & 0.29 & 1.40 & 0.29 \\
\hline & $D_{\text {salt }} * 10^{-5}$ & 2.511 & 2.411 & 2.321 & 2.410 \\
\hline & $\sigma$ & 0.1083 & 0.1027 & 0.2589 & 0.1071 \\
\hline & $\eta \Lambda_{0}$ & 2.34917 & 2.25630 & 2.17128 & 2.25500 \\
\hline
\end{tabular}

* Preferred values.

Units of $\Lambda_{0}: \mathrm{ohm}^{-1} \mathrm{~cm}^{2} \mathrm{~mol}^{-1}, K_{A}: \mathrm{dm}^{3} \mathrm{~mol}^{-1}, a: \mathrm{nm}, D_{\text {salt }}: \mathrm{cm}^{2} \mathrm{~s}^{-1}, \sigma$ : unitless, and $\eta \Lambda_{0}: \mathrm{ohm}^{-1} \mathrm{~cm}^{2} \mathrm{~mol}^{-1} \mathrm{Cp}$.

It was noted that the minimisation $\Lambda_{0}$ and $a$ values for the complete and modified Fuoss-Hsia equations were almost greater than those values obtained using the complete and modified forms of the Pitts. The reason for this has been discussed by Fernandez-Prini and Prue $[15,16]$ in outline, and by Pitts et al. [17] in detail. The Brownian terms in the velocity of the ion were neglected by Pitts. Also, Pitts equation does not allow for the kinetic (osmotic) terms which contributed to the increase in velocity of the ion.

It was obvious from the minimisation technique that the parameter $\Lambda_{0}$ had the greatest effect on the values of $S^{2}$ during the variation of the three parameters $K_{A}, \Lambda_{0}$, and $a$. This is to be expected, in so far as $\Lambda_{0}$ is the leading term in all the conductance equations. However, $\Lambda_{0}$ was relatively insensitive to the values of $K_{A}$ and $a$ at the corresponding minima of $S^{2}$.

Form the association constants given in Tables 5-8, at different temperatures, it can therefore be anticipated that these salts do not behave as "strong" electrolytes, and that their dissociations are far from complete. It can also be seen that copper succinate undergoes more ion-pair formation according to the quantitative conductance data. In conclusion, it appears that the copper succinate is capable of showing a marked tendency to autocomplex formation, similar to the same tendency as for copper malonate $[18,19]$. The high-association constant for the $\mathrm{Cu}(\mathrm{II})$ salt, with the ready availability of d-levels in the cation, illustrates this tendency. At present, however, it is not possible to make a calculation for such complex formation in our computer programs. So, no further analysis was done for this salt. On the above views, it can be generally predicated, for all studied salts, that the degree of dissociation is highly changed from one to another.

The succinate ion possesses the donor property to a less degree than both oxalate and malonate ions [20,21], so it can also be emphasized that succinate salts are more highly dissociated than the oxalates [22] and malonates [23, 24].

In Figures 2, 3, 4, and 5, curves of molar conductance versus square root of concentration at four temperatures have been obtained for the four succinate salts. For these electrolytes, the measured conductivity was abnormally small. Abnormally weak salts usually form autocomplexes readily, as are shown by Ives and Riley's conductivity measurements [25] for copper malonate. In this work, with the exception of copper succinate, however, the experimental conductances give no evidence of this. The same conclusion was found for other systems by other authors [9, 18-24].

Considering the difficulties resulting from the limited solubilities of the succinate salts, the values obtained in this work for $K_{A}, \Lambda_{0}$, and $a$ are satisfactory, providing a particularly good example for typical incompletely dissociated electrolytes, the thermodynamic association constants of 
TABLE 7: Best fit results for Mg-succinate.

\begin{tabular}{|c|c|c|c|c|c|}
\hline Temps. & Parameter & F-H complete ${ }^{*}$ & F-H modified ${ }^{*}$ & Pitts complete & Pitts modified \\
\hline \multirow{6}{*}{$298.15 \mathrm{~K}$} & $\Lambda_{0}$ & 225.20 & 222.60 & 220.00 & 223.00 \\
\hline & $K_{A}$ & 120.0 & 170.0 & 320.0 & 110.0 \\
\hline & $a$ & 0.59 & 1.40 & 0.70 & 0.60 \\
\hline & $D_{\text {salt }} * 10^{-5}$ & 1.499 & 1.481 & 1.464 & 1.484 \\
\hline & $\sigma$ & 0.5177 & 0.2390 & 0.4397 & 0.3709 \\
\hline & $\eta \Lambda_{0}$ & 2.00631 & 1.98314 & 1.95998 & 1.98671 \\
\hline \multirow{6}{*}{$303.15 \mathrm{~K}$} & $\Lambda_{0}$ & 230.00 & 229.20 & 228.00 & 228.20 \\
\hline & $K_{A}$ & 175.0 & 200.0 & 460.0 & 160.0 \\
\hline & $a$ & 0.65 & 1.00 & 0.30 & 0.60 \\
\hline & $D_{\text {salt }} * 10^{-5}$ & 1.556 & 1.551 & 1.543 & 1.544 \\
\hline & $\sigma$ & 0.0975 & 0.0961 & 11.4499 & 0.2885 \\
\hline & $\eta \Lambda_{0}$ & 1.83586 & 1.82947 & 1.81990 & 1.82149 \\
\hline \multirow{6}{*}{$308.15 \mathrm{~K}$} & $\Lambda_{0}$ & 231.80 & 232.00 & 231.60 & 231.40 \\
\hline & $K_{A}$ & 370.0 & 295.0 & 560.0 & 280.0 \\
\hline & $a$ & 1.00 & 1.00 & 1.40 & 0.70 \\
\hline & $D_{\text {salt }} * 10^{-5}$ & 1.594 & 1.596 & 1.593 & 1.592 \\
\hline & $\sigma$ & 0.3931 & 0.9841 & 1.6379 & 1.3726 \\
\hline & $\eta \Lambda_{0}$ & 1.67545 & 1.67690 & 1.67401 & 1.67256 \\
\hline \multirow{6}{*}{$313.15 \mathrm{~K}$} & $\Lambda_{0}$ & 260.00 & 253.20 & 251.20 & 253.80 \\
\hline & $K_{A}$ & 480.0 & 329.0 & 592.0 & 305.0 \\
\hline & $a$ & 1.39 & 1.41 & 1.00 & 1.01 \\
\hline & $D_{\text {salt }} * 10^{-5}$ & 1.817 & 1.770 & 1.756 & 1.774 \\
\hline & $\sigma$ & 0.8112 & 0.6646 & 0.7072 & 0.6792 \\
\hline & $\eta \Lambda_{0}$ & 1.70040 & 1.65593 & 1.64285 & 1.65985 \\
\hline
\end{tabular}

${ }^{*}$ Preferred values.

Units of $\Lambda_{0}: \mathrm{ohm}^{-1} \mathrm{~cm}^{2} \mathrm{~mol}^{-1}, K_{A}: \mathrm{dm}^{3} \mathrm{~mol}^{-1}, a: \mathrm{nm}, D_{\text {salt }}: \mathrm{cm}^{2} \mathrm{~s}^{-1}, \sigma$ : unitless, and $\eta \Lambda_{0}: \mathrm{ohm}^{-1} \mathrm{~cm}^{2} \mathrm{~mol}^{-1} \mathrm{Cp}$.

which conform to the law of mass action. The abnormally low conductances of these electrolytes are not due to the presence of electrically neutral molecules but to the ion-pair formation. This is to be indicated by further measurements at high different frequencies which will be taken into consideration in the future studies. Such evidence has been shown for both oxalate [22] and malonate salts [9], as well as for $\mathrm{Mg}$ and $\mathrm{Mn}$ sulphates [26].

It is obvious from Tables (5-8) that some $a$ values are small, while others are large depending on the type of the four conductance equations used. The explanation for such discrepancies in these results is that the small $a$ values indicate that the linkage is largely covalent $[18,19,27]$ and not merely due to "coulomb" ion association. The large $a$ values were explained by the fact that the assumption of spherical symmetry and a central charge is far from truth for the succinate ion just like that in barium malonate $[18,19]$.

Recently, an investigation of $\mathrm{Mg}, \mathrm{Ca}$, and $\mathrm{Ba}$ complexes in aqueous solution was carried out [28]. The result showed that the conductance of $\mathrm{Mg}^{+2}$ ion is much lower due to greater interaction between the charge on the ion and the dipoles of the adjacent solvent molecules, which leads to a reduction in mobility. A good agreement between their values of $\Lambda_{0}$ for $\mathrm{Mg}$ and $\mathrm{Ba}$ succinates and our present values was obtained for both salts.
Unfortunately, no recent determinations of $\Lambda_{0}$ at $298.15 \mathrm{~K}$ for all salts studied have been found. So, in comparison with ionic mobilities at infinite dilution at $298.15 \mathrm{~K}$ taken from [14]: $\lambda_{01 / 2} \mathrm{Mg}^{+2}=53.06, \lambda_{01 / 2} \mathrm{Mn}^{+2}=53.10, \lambda_{01 / 2} \mathrm{Ba}^{+2}=$ 63.64, and $\lambda_{01 / 2} \mathrm{Cu}^{+2}=53.60$ together with the value of 58.8 [14] or 56.99 [29] of succinate ion, good agreement has been shown in Tables 5-8.

In order to obtain a better understanding of the thermodynamics of the association reactions for the studied salts, it is useful to consider the enthalpic and entropic contributions to these associations. The standard enthalpy, free energy and entropy changes were determined by using (3) and (4), respectively, at different temperatures. Summarizing at this point, give the conductometric association constant $K_{A}$, the standard free energy change for the postulated equilibrium can be determined. This opens the way to a search for correlations between $\Delta G^{\circ}, \Delta H^{\circ}$, and $\Delta S^{\circ}$ on the one hand and basic properties of solutes and solvents on the other hand. According to the minimisation technique used here, each of the seven systems gave a unique best set of parameters at each temperature. While the best $K_{A}$ and $\Lambda_{0}$ showed an expected trend with temperature, this trend for $a$ was quite irregular and covered a broader range of values. Tables 5-8 show clearly the temperature dependence of the $\Lambda_{0}$ of particular systems. The increase of $\Lambda_{0}$ with an increase of temperature 
TABLE 8: Best fit results for Mn-succinate.

\begin{tabular}{|c|c|c|c|c|c|}
\hline Temps. & Parameter & F-H complete ${ }^{*}$ & F-H modified ${ }^{*}$ & Pitts complete & Pitts modified \\
\hline \multirow{6}{*}{$298.15 \mathrm{~K}$} & $\Lambda_{0}$ & 224.80 & 220.00 & $220.40-220.80$ & 223.40 \\
\hline & $K_{A}$ & 353.0 & 490.0 & 850.0 & 550.0 \\
\hline & $a$ & 0.65 & 1.10 & 0.30 & 0.65 \\
\hline & $D_{\text {salt }} * 10^{-5}$ & 1.496 & 1.464 & 1.468 & 1.487 \\
\hline & $\sigma$ & 0.2028 & 0.1772 & 0.3644 & 0.3928 \\
\hline & $\eta \Lambda_{0}$ & 2.00274 & 1.95998 & 1.96533 & 1.99027 \\
\hline \multirow{6}{*}{$303.15 \mathrm{~K}$} & $\Lambda_{0}$ & 226.30 & 225.80 & 228.00 & 226.00 \\
\hline & $K_{A}$ & 500.0 & 525.0 & 950.0 & 553.0 \\
\hline & $a$ & 0.60 & 1.20 & 0.30 & 0.75 \\
\hline & $D_{\text {salt }} * 10^{-5}$ & 1.531 & 1.528 & 1.543 & 1.530 \\
\hline & $\sigma$ & 0.4441 & 0.5212 & 0.7283 & 0.8156 \\
\hline & $\eta \Lambda_{0}$ & 1.80633 & 1.80234 & 1.81990 & 1.80393 \\
\hline \multirow{6}{*}{$308.15 \mathrm{~K}$} & $\Lambda_{0}$ & 232.80 & 229.80 & 230.60 & 230.00 \\
\hline & $K_{A}$ & 680.0 & 580.0 & 990.0 & 555.0 \\
\hline & $a$ & 1.00 & 1.10 & 0.30 & 0.80 \\
\hline & $D_{\text {salt }} * 10^{-5}$ & 1.601 & 1.581 & 1.586 & 1.582 \\
\hline & $\sigma$ & 0.5795 & 0.4829 & 0.7623 & 0.5641 \\
\hline & $\eta \Lambda_{0}$ & 1.68268 & 1.66099 & 1.66678 & 1.66244 \\
\hline \multirow{6}{*}{$313.15 \mathrm{~K}$} & $\Lambda_{0}$ & 246.00 & 239.60 & 240.00 & 242.60 \\
\hline & $K_{A}$ & 820.0 & 590.0 & 1010.0 & 585.0 \\
\hline & $a$ & 1.40 & 1.41 & 0.30 & 0.71 \\
\hline & $D_{\text {salt }} * 10^{-5}$ & 1.720 & 1.675 & 1.678 & 1.696 \\
\hline & $\sigma$ & 0.4200 & 0.5529 & 0.5570 & 0.7734 \\
\hline & $\eta \Lambda_{0}$ & 1.60884 & 1.56698 & 1.56960 & 1.58660 \\
\hline
\end{tabular}

* Preferred values.

Units of $\Lambda_{0}: \mathrm{ohm}^{-1} \mathrm{~cm}^{2} \mathrm{~mol}^{-1}, K_{A}: \mathrm{dm}^{3} \mathrm{~mol}^{-1}, a: \mathrm{nm}, D_{\text {salt }}: \mathrm{cm}^{2} \mathrm{~s}^{-1}, \sigma$ : unitless, and $\eta \Lambda_{0}: \mathrm{ohm}^{-1} \mathrm{~cm}^{2} \mathrm{~mol}^{-1} \mathrm{Cp}$.

TABLE 9: Thermodynamic data for Ba-succinate.

\begin{tabular}{|c|c|c|c|c|c|c|c|c|c|}
\hline & \multirow{2}{*}{$\Delta H^{\circ}\left(\mathrm{kJ} \mathrm{mol}^{-1}\right)$} & \multicolumn{4}{|c|}{$\Delta G^{\circ}\left(\mathrm{kJ} \mathrm{mol}^{-1}\right)$} & \multicolumn{4}{|c|}{$\Delta S^{\circ}\left(\mathrm{J} \mathrm{K}^{-1} \mathrm{~mol}^{-1}\right)$} \\
\hline & & $298.15 \mathrm{~K}$ & $303.15 \mathrm{~K}$ & $308.15 \mathrm{~K}$ & $313.15 \mathrm{~K}$ & $298.15 \mathrm{~K}$ & $303.15 \mathrm{~K}$ & $308.15 \mathrm{~K}$ & $313.15 \mathrm{~K}$ \\
\hline F-H complete & 69.681 & -12.159 & -13.116 & -15.475 & -15.934 & 274.493 & 273.122 & 276.346 & 273.400 \\
\hline F-H modified & 42.614 & -11.740 & -13.548 & -14.276 & -14.524 & 182.303 & 185.260 & 184.617 & 182.461 \\
\hline Pitts complete & 32.510 & -13.968 & -14.978 & -15.535 & -16.380 & 155.887 & 156.647 & 155.913 & 156.122 \\
\hline Pitts modified & 35.069 & -10.800 & -11.076 & -12.042 & -13.045 & 153.846 & 152.219 & 152.884 & 153.646 \\
\hline
\end{tabular}

TABLE 10: Thermodynamic data for $\mathrm{Cu}$-succinate.

\begin{tabular}{lccccccccc}
\hline & \multirow{2}{*}{$\Delta H^{\circ}\left(\mathrm{kJ} \mathrm{mol}^{-1}\right)$} & \multicolumn{4}{c}{$\Delta G^{\circ}\left(\mathrm{kJ} \mathrm{mol}^{-1}\right)$} \\
& & $298.15 \mathrm{~K}$ & $303.15 \mathrm{~K}$ & $308.15 \mathrm{~K}$ & $313.15 \mathrm{~K}$ & $298.15 \mathrm{~K}$ & $303.15 \mathrm{~K}$ & $308.15 \mathrm{~K}$ & $313.15 \mathrm{~K}$ \\
\hline F-H complete & 37.950 & -23.199 & -24.445 & -25.117 & -26.396 & 168.065 & 168.450 & 173.372 & 172.070 \\
F-H modified & 35.414 & -22.954 & -24.239 & -24.768 & -26.044 & 158.155 & 161.510 & 161.252 & 159.469 \\
Pitts complete & 34.494 & -23.090 & -24.551 & -25.102 & -26.125 & 162.542 & 163.193 & 162.353 & 162.459 \\
Pitts modified & 39.125 & -22.843 & -24.159 & -24.832 & -26.085 & 167.448 & 165.597 & 166.045 & 166.597 \\
\hline
\end{tabular}

TABLE 11: Thermodynamic data for Mg-succinate.

\begin{tabular}{|c|c|c|c|c|c|c|c|c|c|}
\hline & \multirow{2}{*}{$\Delta H^{\circ}\left(\mathrm{kJ} \mathrm{mol}^{-1}\right)$} & \multicolumn{4}{|c|}{$\Delta G^{\circ}\left(\mathrm{kJ} \mathrm{mol}{ }^{-1}\right)$} & \multicolumn{4}{|c|}{$\Delta S^{\circ}\left(\mathrm{J} \mathrm{K}^{-1} \mathrm{~mol}^{-1}\right)$} \\
\hline & & $298.15 \mathrm{~K}$ & $303.15 \mathrm{~K}$ & $308.15 \mathrm{~K}$ & $313.15 \mathrm{~K}$ & $298.15 \mathrm{~K}$ & $303.15 \mathrm{~K}$ & $308.15 \mathrm{~K}$ & $313.15 \mathrm{~K}$ \\
\hline F-H complete & 76.249 & -11.867 & -13.017 & -15.150 & -16.074 & 296.520 & 294.787 & 297.659 & 294.372 \\
\hline F-H modified & 36.812 & -12.731 & -13.354 & -14.570 & -15.090 & 162.843 & 166.122 & 165.789 & 163.933 \\
\hline Pitts complete & 31.863 & -14.299 & -15.453 & -16.212 & -16.620 & 153.717 & 154.514 & 153.814 & 154.056 \\
\hline Pitts modified & 56.333 & -11.652 & -12.791 & -14.436 & -14.893 & 225.165 & 222.361 & 221.888 & 221.548 \\
\hline
\end{tabular}


TABLE 12: Thermodynamic data for Mn-succinate.

\begin{tabular}{lccccccccc}
\hline & \multirow{2}{*}{$\Delta H^{\circ}\left(\mathrm{kJ} \mathrm{mol}^{-1}\right)$} & \multicolumn{4}{c}{$\Delta G^{\circ}\left(\mathrm{kJ} \mathrm{mol}^{-1}\right)$} & \multicolumn{4}{c}{$\Delta S^{\circ}\left(\mathrm{J} \mathrm{K}^{-1} \mathrm{~mol}^{-1}\right)$} \\
& & $298.15 \mathrm{~K}$ & $303.15 \mathrm{~K}$ & $308.15 \mathrm{~K}$ & $313.15 \mathrm{~K}$ & $298.15 \mathrm{~K}$ & $303.15 \mathrm{~K}$ & $308.15 \mathrm{~K}$ & $313.15 \mathrm{~K}$ \\
\hline F-H complete & 44.111 & -14.542 & -15.663 & -16.709 & -17.468 & 188.730 & 188.774 & 193.366 & 191.745 \\
F-H modified & 10.223 & -15.355 & -15.786 & -16.302 & -16.611 & 73.663 & 78.412 & 79.503 & 79.025 \\
Pitts complete & 8.720 & -16.720 & -17.281 & -17.672 & -18.010 & 76.095 & 78.171 & 78.710 & 80.152 \\
Pitts modified & 2.906 & -15.641 & -15.903 & -16.189 & -16.589 & 45.969 & 46.121 & 48.508 & 50.936 \\
\hline
\end{tabular}

is due to the decrease of solvent viscosity. Bearing in mind that dielectric constant decreases as temperature increases, an increase in temperature should play important role in stabilizing ion-pairs of reaction. So, $K_{A}$ increases as shown in the same mentioned tables. Furthermore, when the dielectric constant of the solvent becomes smaller as temperature increases, the electrostatic contribution dominates. As a consequence, many complexes become significantly stable at high temperatures [30]. The same trend was found by Franchini et al. [31] for a conductometric study of dissociation of picric acid in two different organic solvents at different temperatures, as well as by Sokol et al. [13] in their study for the thermodynamics of the association reaction conductance measurements.

Standard thermodynamic quantities for the association reaction of metal ion $\left(\mathrm{M}^{+2}\right)$ and succinate ions are obtained from the temperature dependence of $K_{A}$, (3), as given in Tables 9, 10, 11, and 12 .

The positive entropy values of the associations indicate a change from more order states towards a less order states. This might reflect the role of solvent in the association process.

The above-mentioned results show that the $\Delta H^{\circ}$ term is the most important factor in determining the stability of the association, and the differences in the magnitude of $\Delta H^{\circ}$ values reflected the differences in the attractive forces between opposite charges of the ions of ion-pair.

Many difficulties and uncertainties are associated with these calculations which are derived from the inevitable experimental errors in $K_{A}$ values and partly from the calculator's choice of the function which represents the dependence on the temperature. However, the values of $\Delta G^{\circ}$ have proved useful in yielding structural information about solute species and solute-solvent interactions. So, such values indicate a spontaneous association of ions (i.e., the yield of ion-pairs increases) despite of that they differ from one equation to the other depending on their mathematical derivations.

From the dependence of the Walden product $\eta \Lambda_{0}$ on the temperature, information can be obtained on ion-solvent interactions. Data from Tables 5-8 show that the Walden product dependence on the temperature is substantially obeyed. For more consistent results, a consideration should be taken for the electrostatic interaction between the fields of the moving ions and those of the solvent dipoles in the surrounding solvent. The gradual decrease of $\eta \Lambda_{0}$ with temperature has been attributed to a decrease in dielectric constant, causing a disturbance in the hydrodynamic radii of ions followed by a change in their mobility.
Generally, it is concluded that either Fuoss-Hsia complete or modified is better than those equations of Pitts.

\section{Acknowledgment}

With affection and deep appreciation the authors acknowledge their indebtedness to: Mr. Salam G. Tahir for doing CHN and HNMR measurements for the prepared compounds in University of Wales-Bangor (UWB), UK.

\section{References}

[1] A. A. AL-Najar and A. M. Ibrahim, "The audio frequency conductances of magnesium, manganese II, and barium malonates in aqueous medium at $25^{\circ} \mathrm{C}$," Canadian Journal of Chemistry, vol. 68, no. 5, pp. 770-773, 1990.

[2] M. Ue and S. Mori, "Mobility and ionic association of lithium salts in a propylene carbonate-ethyl methyl carbonate mixed solvent," Journal of the Electrochemical Society, vol. 142, no. 8, pp. 2577-2581, 1995.

[3] M. F. Bakr and A. A. Mohamed, Journal of the Chinese Chemical Society, vol. 46, pp. 899-904, 1999.

[4] M. F. Bakr, Chinese Journal of Chemistry, vol. 48, pp. 1087-1091, 2001.

[5] Reference Internet: PDR, For Nutritional Supplements, Amjrenal physiol, 1 st edition, 2000.

[6] Reference Internet (10-2-2008), 1997, http//en.Wikipedia.Org/ Wiki/succinate-dehydrogenase.

[7] P. Prapaipong, E. L. Shock, and C. M. Koretsky, "Metalorganic complexes in geochemical processes: temperature dependence of the standard thermodynamic properties of aqueous complexes between metal cations and dicarboxylate ligands," Geochimica et Cosmochimica Acta, vol. 63, no. 17, pp. 2547-2577, 1999.

[8] E. V. Ikhaoria, F. E. Okieimen, and A. I. Aigbodion, "Evaluation of the effect of temperature on the stability of metal soaps of dicarboxylic acids," Journal of Applied Sciences and Environmental Management, vol. 9, no. 1, pp. 127-130, 2005.

[9] A. M. Ibrahim, [M.S. thesis], University of Basrah, Basrah, Iraq, 1978.

[10] H. A. Flascka, A. J. Bamard Jr., and P. E. Sturrock, Quantitative Analytical Chemistry, vol. 2, 1969.

[11] C. Livage, C. Egger, and G. Ferey, "Hydrothermal versus nonhydrothermal synthesis for the preparation of organic-inorganic solids: the example of cobalt(II) succinate," Chemistry of Materials, vol. 13, pp. 410-414, 2001.

[12] A. I. Vogel, Practical Organic Chemistry, Longmans, Green, and Co., 3rd edition, 1966. 
[13] V. Sokol, I. Tominic, R. Tomus, and M. Visic, "Thermodynamics of the association reaction of $\mathrm{Li}_{+}$and $\mathrm{Br}_{-}$ions in 2-butanol + water mixtures from conductivity measurements," Croatica Chemica Acta, vol. 78, no. 1, pp. 43-47, 2005.

[14] O. Sacks, Hand Book of Chemistry and Physics, 85th edition, 2003.

[15] R. Fernandez-Prini and J. E. Prue, The Journal of Physical Chemistry, pp. 228-373, 1965.

[16] R. Fernandez-Prini, "Conductance of electrolyte solutions: a modified version of its concentration dependence," Transactions of the Faraday Society, vol. 65, pp. 3311-3313, 1969.

[17] E. Pitts, B. E. Tabor, and J. Daly, Transactions of the Faraday Society, vol. 65, p. 849, 1969.

[18] D. I. Stock and C. W. Davies, "The colorimetric measurement of $\mathrm{pH}$, and the dissociation constants of the malonates of some bivalent metals," Journal of the Chemical Society, pp. 1371-1374, 1949.

[19] J. M. O. Peacock and J. C. James, Journal of the Chemical Society, p. 2233, 1951.

[20] A. A. AL-Najar and A. M. Ibrahim, "The audio frequency conductances of magnesium, manganese II, and barium malonates in aqueous medium at $25^{\circ} \mathrm{C}$," Canadian Journal of Chemistry, vol. 68, no. 5, pp. 770-773, 1990.

[21] H. L. Riley and N. I. Fisher, Journal of the Chemical Society, vol. 1929, 2006.

[22] A. Al-Najar, [Ph.D. thesis], University of Surrey, 1974.

[23] A. M. Ibrahim, [M.S. thesis], University of Basrah, Basrah, Iraq, 1978.

[24] T. L. Bear and Chin-Ting-Lin, The Journal of PhysicalChemistry, vol. 72, 1968.

[25] D. J. G. Ives and H. L. Riley, Journal of the Chemical Society, vol. $11,1931$.

[26] W. H. Lee, R. W. Pengilly, and R. W. Rance, Zeitschrift für Physikalische Chemie-Leipzig, vol. 257, no. 3, p. 433, 1976.

[27] R. H. Jones and D. I. Stock, "The dissociation constants in water of some bivalent metal alkanedicarboxylates," Journal of the Chemical Society, pp. 306-311, 1962.

[28] M. F. Bark and A. A. Mohamed, "Investigation of magnesium (II), calcium (II) and barium (II) complexes in Aqueous solution," Qatar University Science Journal, vol. 25, pp. 88-97, 2005.

[29] A. Apelblat, "Dissociation constants and limiting conductances of organic acids in water," Journal of Molecular Liquids, vol. 95, no. 2, pp. 99-145, 2002.

[30] H. C. Helgeson, "Thermodynamics of complex dissociation in aqueous solution at elevated temperatures," Journal of Physical Chemistry, vol. 71, no. 10, pp. 3121-3136, 1967.

[31] G. Franchini, E. Ori, C. Preti, L. Tassi, and G. Tosi, "A conductometric study of dissociation of picric acid in 2-methoxyethanol and 1,2-ethanediol from -10 to $80{ }^{\circ} \mathrm{C}$," Canadian Journal of Chemistry, vol. 65, pp. 722-726, 1987. 

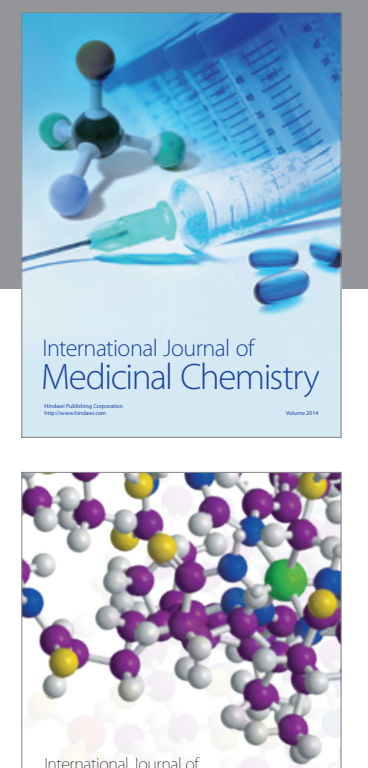

\section{Carbohydrate} Chemistry

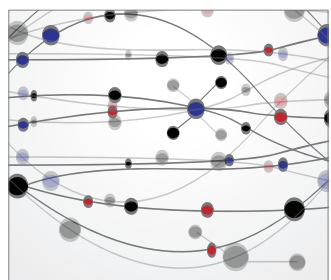

The Scientific World Journal
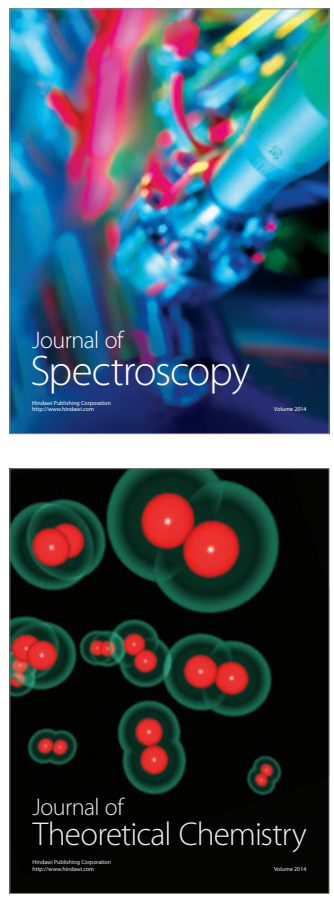
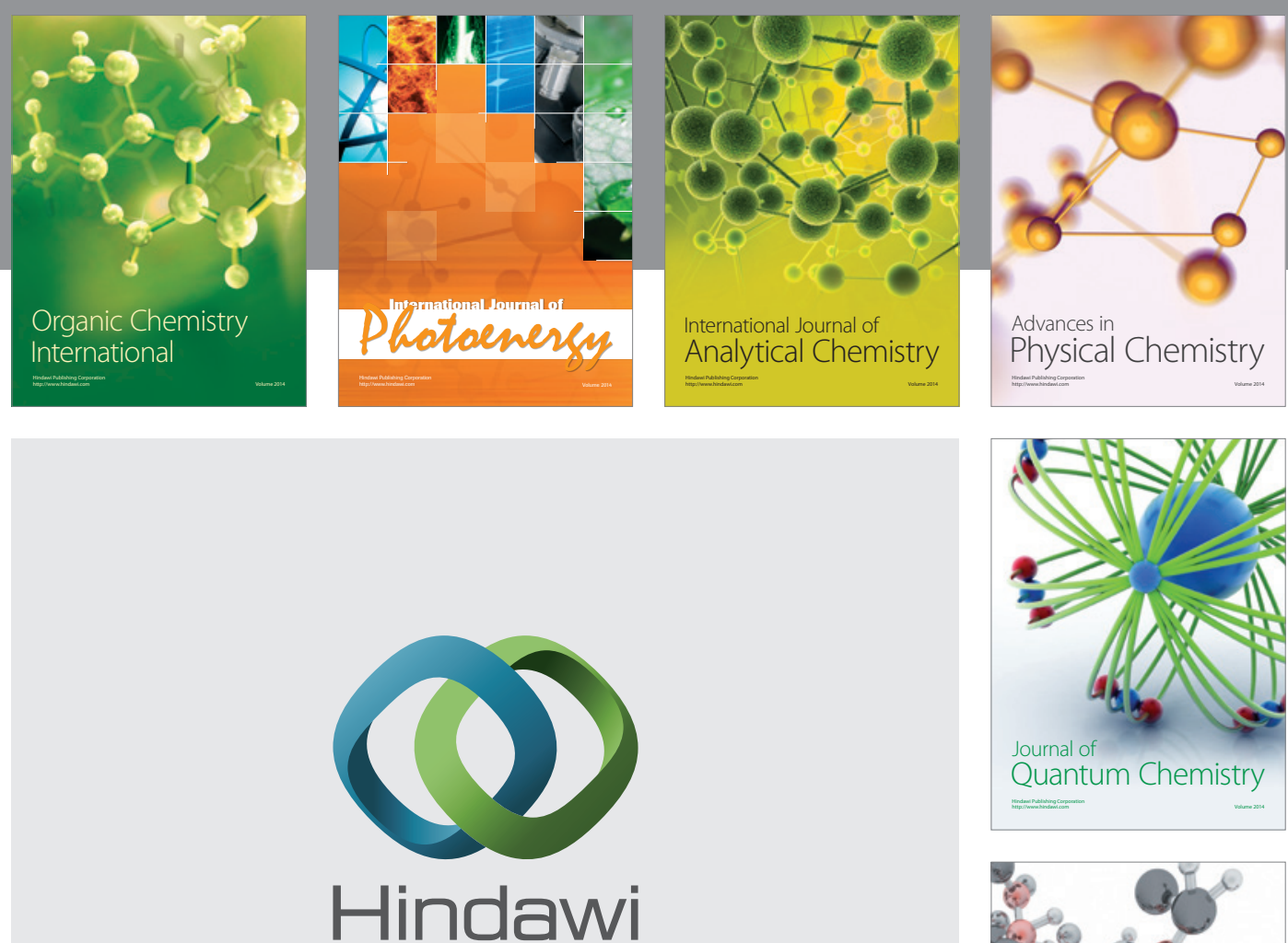

Submit your manuscripts at

http://www.hindawi.com

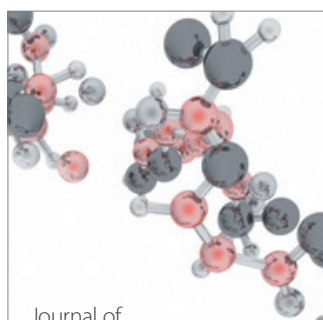

Analytical Methods

in Chemistry

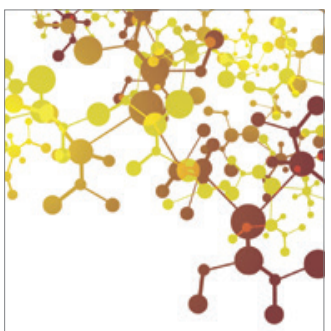

Journal of

Applied Chemistry

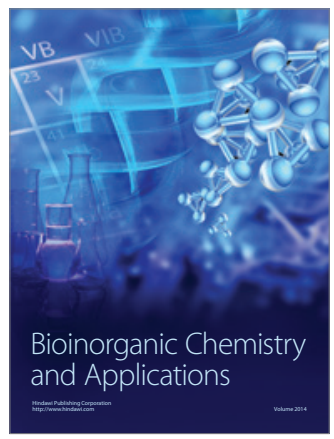

Inorganic Chemistry
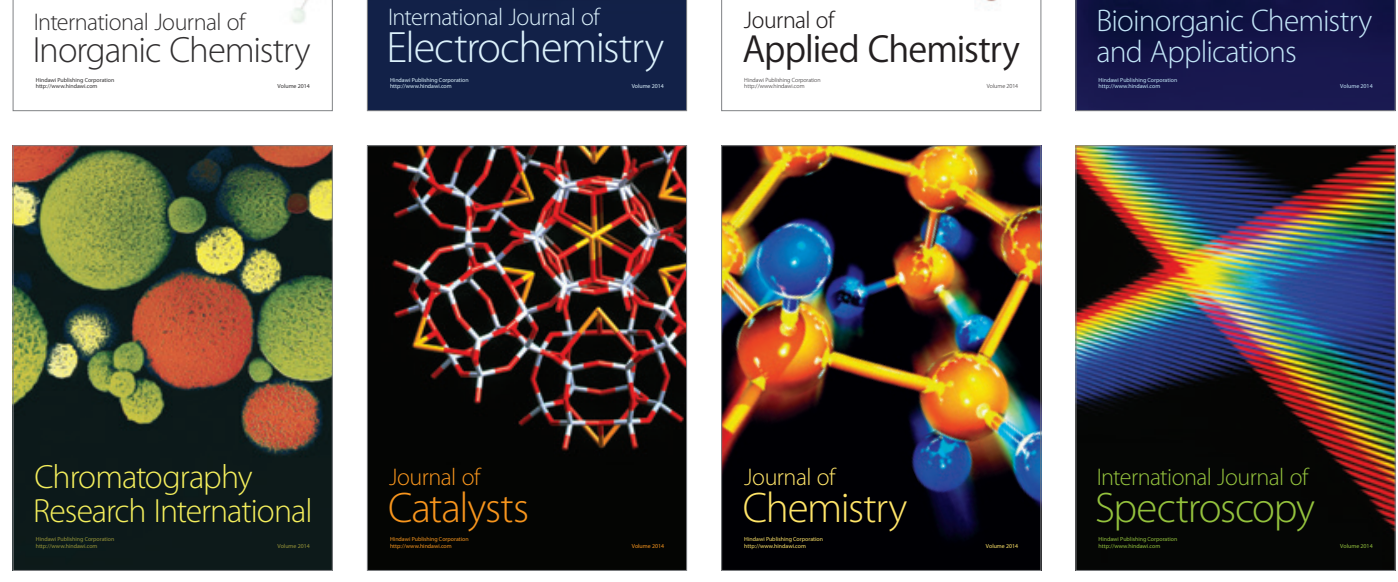